\title{
EFFICIENCY OPTIMIZATION OF ATTENDANCE SYSTEM WITH GPS AND BIOMETRIC METHOD USING MOBILE DEVICES
}

\author{
Benfano Soewito ${ }^{1}$; Echo Wahana Marciano Simanjuntak ${ }^{2}$ \\ ${ }^{1,2}$ Master of Information System Management, Binus Graduate Programs, Bina Nusantara University \\ Jl KH Syahdan 9, Jakarta 11480, Indonesia. \\ solar_medan@yahoo.com and benfano@gmail.com
}

\begin{abstract}
The existing attendance system still has drawbacks, namely the queue in front of the finger scanner, the attendance data are not integrated with Human Resources Systems, and also the employees who work outside the office cannot get in the attendance system to roll presence. In the other hand, everyone has the mobile devices and all the mobile devices will be embedded a finger scanner in the future. In this paper, it is proposed the absence system using one own device. The finger scanner and coordinate Global Position System (GPS) are used as inputs for the attendance system that integrated with payroll system and human resource management tools. Application base on android platform is developed because the android is the most platforms that have been using in the most mobile devices. Using our proposed methodology, the employee can roll presence using their mobile devices and the do not need to be in queue and the employees who work outside the office also can roll presence. Research showed that proposed methodology can be used for the next generation attendance system.
\end{abstract}

Keywords: Absence system, Finger print analysis, Mobile devices

\section{INTRODUCTION}

At this time the attendance is mostly done either by hand or by electronic (fingerprint scanners are widely used by companies today). These methods have limitations in processing the data, for example when the company has a payroll system, and then the system operator must enter the employee attendance data manually, then the attendance will be difficult to integrate with systems owned by the company. The next limitation is encountered when the company also has a project with worker outside of the building company. Our proposed method is expected to provide a solution for using GPS coordinate obtained through the mobile devices that owned by employees. The GPS coordinate sent to payroll system as the data where the location of the employee. The next issue is expected to overcome the problems that often occur, such as cheating. The employee asking friends to fill the attendance his/her friends (often referred to as illegal attendance and usually occurs in the attendance manual systems). Therefore, it needs a better system to tackle the problems of attendance system to be more effective, more accurate, and can be integrated with payroll system.

In this paper, it is proposed online attendance system on one own mobile devices and is integrated with the payroll system. The proposed method is a system created to overcome some of the limitations that occur in manual or electronic attendance system which is often conventionally used today. Our study also aims to provide a solution to the problems of employee performance. It will be able to give an exact picture of the performance of the employees of the company, provide the optimization and efficiency of the payroll system which is a system that is useful notes any data regarding employee attendance data from each respective company. In the long-term use is expected to help improve the company's performance.

\section{LITERATURE REVIEW}

\section{Biometric and finger print}

The word biometrics comes from the Greek bios and metrics, bios meaning is life, and metrics, which means the size [1]. Biometrics can be defined as a characteristic physiological and behavioral that can be utilized to verify the identity of an individual, and includes verification of fingerprints, hand geometry, retinal scans, iris scans, facial recognition and signature verification [2]. Biometric authentication is known as automatic identification, or verification of identity, of an individual using a biological feature that has physiological characteristics such as a fingerprint or something done that have behavioral characteristics, such as a signature [3]. In practice, 
the process of identification and authentication is the ability to verify and confirm the identity and solved by using one or a combination of the three traditional identification techniques: something you have; something that you know; or something that is you [4], [5].

Fingerprint biometrics is one form, a science that uses physical characteristics to identify a person [6], [7]. Finger print is ideal for this purpose because it is easy to be collected and analyzed, and has never changed even though the person's age. Fingerprint matching has been successfully used by law enforcement for more than a century [8], [9].

\section{Human Resources Information System (HRIS)}

The Human Resources Information System is a software or online solution for the data entry, the data tracking, and data information needed for human resources, payroll, management, and accounting functions in business. Hundreds of companies sell HRIS and each HRIS has different characteristics. It depends on the hardware and finger print scanner that they use. Our proposed HRIS can be integrated with any finger print scanner. It's easy to use and can be customized.

\section{Android finger print scanner}

Mobile device is considered to be a valuable tool in conducting various activities due to their small size and has a good ability to support a variety of activities [10]. One of the mobile operating system that is widely used these days is the Android OS from Google, even according to the survey that has been conducted, the Android operating system became the most popular and most widely used today [11], [12]. To implement our proposed methodology of the making of the attendance system, we need a device that has the ability to perform biometric methods and the ability to take the position or coordinates of the user and at the moment there is an Android device that is capable of doing that.

\section{METHOD}

Our research method used experimental design. Firstly, observations of the existing payroll system is conducted and its relationship with the current attendance system; this is done in order to know how the integration is performed and the effectiveness of existing integration between the payroll system and attendance (absence) system. After, the observations and analysis are done, and then it proceeded with the manufacture of mobile applications based attendance system using the android operating system.

\section{Research tools}

In this research tools as shown in table 1 is used. First, all employee finger print is captured using a finger print scanner [13] and saved these information as a database finger print. Android tab was used to evaluate matching finger print system; the finger print from this tab will be matched to the data base finger print.

Some software or programming languages are also used to complete our system such as PostgreSQL Database and Eclipse IDE. All the application installed in web server and web services.

\section{Data Analysis}

The results of the experiment will produce a certain amount of data that can be analyzed related to the accuracy of the data, so that the desired results can be said to have been achieved. The data analysis was performed are as follows:

Table 1: Research tools

\begin{tabular}{ll}
\hline Device & Specifications \\
\hline Finger print scanner & USB Finger print scanner \\
Android Tab & Samsung Galaxy Tab 2 7 \\
& inch P3100 Android 4.0.4 \\
& Ice Cream Sandwich (API \\
& level 15) \\
& 350 MB disk space, 25 \\
Hosting, payroll, and web & GB data transfer, 512 \\
service Server & virtual memory limit \\
& Application HRIS \\
Postgresql Database & Database \\
& Editor for application \\
Eclipse IDE & source code \\
& \\
\hline
\end{tabular}

- After the user did attendance process at the mobile device used finger print scanner, then the data will be examined further in the payroll application.

- Matching related to the user of GPS positioning at the time doing attendance, conduct user profiles attendance, as well as the related working hours data, overtime, shift and other functions in the payroll system.

- Upon analyze the data in the payroll application is done, and then it will continue with the analyze data on the absence (attendance) application on a mobile device where the application is also can displays data on the payroll but limited, only on users who access the application.

- The next step is to analyze the calculation results of the absence payroll application is made whether the user is in conformity with the method of calculating payroll result.

- Perform printing payroll related reports of users that exist in the system so that the purpose of calculating the payroll system is reached. 


\section{Application Module}

Employee module is a payroll application module that serves to manage employee data, such as employee registering, deleting the list of employees, employee groups, etc. To enroll this system, an employee has to do two steps processes. First, prospective employees must enroll through their android device using existing attendance application on the device, then the second step, the admin of payroll application will complement the data of the prospective employees and prospective employees have registered to be employees be able to use the features available in this application.

\section{Absence Application on Android Device}

Our proposed application runs on android devices connected to employee payroll application on the admin side through an internet connection. This application will take the user position used the GPS module that is available on the android device [14], [15]. Moreover, the application also do match the user's fingerprint stored in a database server and retrieve the date and time when the user is doing absent [16], [17], [18]. Our method will increase the accuracy of the attendance system for taking a position, date and time in real time. The use of user identification using fingerprint method will also reduce possible fraud because the user cannot leave the device he has done to others for attendance.

In addition to absence application, the employee can also find the information related to data at HRIS, such as total working hour, total overtime, and payroll report. The flow chart of this application is shown in figure 1. The information regarding to HRIS also can be seen through web that using HTML code.

\section{Modified matching finger print algorithm}

In this paper, matching finger print algorithm that introduced by reff. [6] is used. But the algorithm is modified to run faster. Algorithm is modified in processing data, only one area is taken for matching finger print. The flow chart of modified matching finger print algorithm was shown in figure 2 .

As seen in figure 2, the first step is finger print image preparing. In this step we take width and height fingerprint image that will be analyzed and used as a comparison with database fingerprint image. The width and height of the image has to be taken to determine the array that is used to accommodate a byte array from each pixel. Then, the gray level of each pixel is taken and the gray value of each pixel has to be calculated and stored into a two-dimensional array.

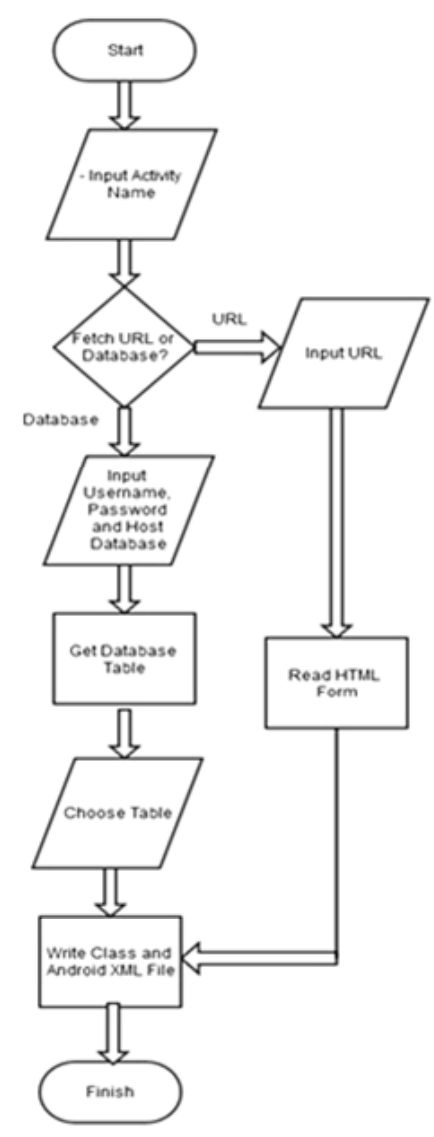

Fig.1: Flow Chart of User Application

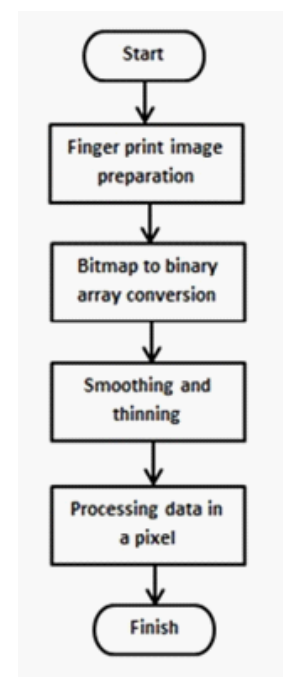

Fig.2: Flow chart of finger print matching

Converting bitmap to binary array is done because the analysis will be much easier to do. The binary arrays have only two values which are true or false, where true means the pixel is black and white pixel means false. Giving a value of true or false based on whether the pixel has a gray value greater 
than the overall average of gray level or not. It will be set false if the level is greater than average and vice versa.

Smoothing process is needed to took out the noise on the bitmap and can be reduced the noise thereby increasing the accuracy.

Thinning process is done by reff. [6] algorithm but the algorithm has to be modified in order to be optimized for the algorithm run faster. The first step is to divide the fingerprint image into 9 regions, then each region examined which parts have a byte array of pixels meeting true and false, each meeting will add value to the region as one. Then the part that has the most true and false byte meetings is what will be in thinning, so it is not necessary to thinning process at all the pixel, but all the result is stored as data for later comparison with other fingerprint image.

When the pixel comparison is done it will be checked how many percent of the degree of similarity between the two images. The greater the degree of similarity is determined the more accurate level of similarity.

\section{RESULTS AND DISCUSSION}

Based on 20 attempts in 20 respondents, we found the matching percentage of respondents compare to my finger print shown in table 2 . The table showed that our proposed matching finger algorithm can be used in our system absence because all the result is less than $50 \%$.

Table 2: Matching finger print

\begin{tabular}{clc}
\hline No. & Respondent & Matching Percentage \\
\hline 1 & Respondent 1 & $2.00 \%$ \\
2 & Respondent 2 & $2.60 \%$ \\
3 & Respondent 3 & $0.50 \%$ \\
4 & Respondent 4 & $3.64 \%$ \\
5 & Respondent 5 & $3.38 \%$ \\
6 & Respondent 6 & $8.07 \%$ \\
7 & Respondent 7 & $9.11 \%$ \\
8 & Respondent 8 & $0.26 \%$ \\
9 & Respondent 9 & $23.43 \%$ \\
10 & Respondent 10 & $1.30 \%$ \\
11 & Respondent 11 & $1.56 \%$ \\
12 & Respondent 12 & $0.26 \%$ \\
13 & Respondent 13 & $4.42 \%$ \\
14 & Respondent 14 & $14.50 \%$ \\
15 & Respondent 15 & $7.81 \%$ \\
16 & Respondent 16 & $13.80 \%$ \\
17 & Respondent 17 & $3.38 \%$ \\
18 & Respondent 18 & $24.82 \%$ \\
19 & Respondent 19 & $5.12 \%$ \\
20 & Respondent 10 & $21.87 \%$ \\
\hline & & \\
\hline
\end{tabular}

As shown in figure 3, there are several menus on the main screen applications, such as About Application (Tentang aplikasi) and Registration (Registrasi), which is classified as a menu bar. Then there are two more menus that is classified as a main menu: Attendance (Presensi) and Payroll \& Schedule (Payroll \& Jadwal) which was made using the button.

When users want to use this application, firstly the device and user data have to be registered in the employee payroll application on the admin side, if the user has not registered, it can choose the registration menu form as shown in figure 4.

The user must first active the finger print scanner on their devices or if the devices do not have finger print scanner, they can connect to the external finger print scanner. Then put his finger over the fingerprint sensor and press a button that will send the data capture device and a fingerprint scan results to the server, the server will check if the device has been previously registered or not and send the response returns the device.

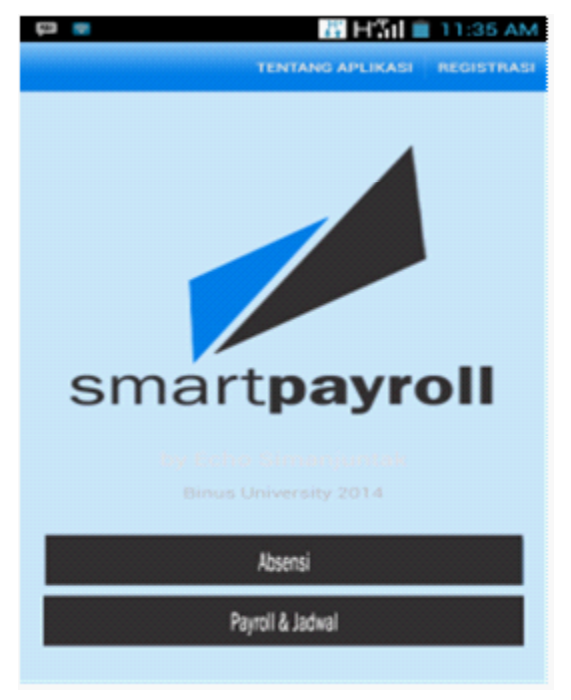

Fig.3: Screen on the mobile device

\section{CONCLUSION}

- Fingerprint as one way to do identification employee and can be collaborated with GPS and mobile technologies to create an accurate attendance applications.

- Method comparison/matching fingerprint can still be optimized by using image segmentation on the fingerprint. Then transform pixels into a binary array and compare based binary so that it can expedite and accelerate matching process. Some of the methods that can be removed to optimize the matching time are the search direction and method of detecting fingerprint ridge detail/minute as fingerprint ridge ending and bifurcation. 
- $\quad$ Our proposed method can solved the issues that came up in conventional absence or attendance system such as the queue in front of the finger scanner, the absence data are not integrated with Human Resources Systems, the employees who work outside the office that cannot do attendance, and cheating (The employee asking friends to fill the attendance his/her friend)

- The proposed absence system also can save the cost to provide and maintain the finger print scanner because the employee will use their own devices to do the attendance.

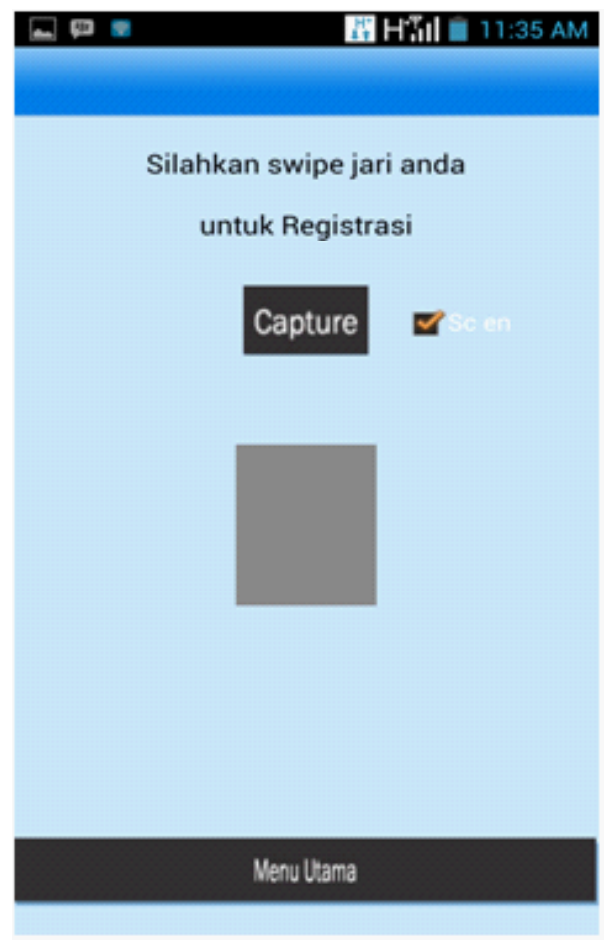

Fig.4: Screen to do registration and finger print

\section{REFERENCES}

[1] Ashbourn, J., Biometrics: Advanced Identity Verification: The Complete Guide. Springer-Verlag, London, .. 2000:Springer. 201.

[2] Wayman, J.L. and L.Alyea, Picking the Best Biometric for Your Applications, in National Biometric Test Center Collected Works. 2000, National Biometric Test Center: San Jose. p. 269-275.

[3] Pfleeger C.P.,Security in computing. second edition ed. 1997: Prentice Hall PTR.

[4] Tiwana, A.,Web Security. 1999: Digital Press An imprint of Butterworth-Heinemann.

[5] Prabhakar, S., S. Pankanti, and A.K. Jain, Biometrics Recognition: Security and Privacy Concerns. IEEE Security \&Privacy, 2003.1(2): p. 33-42.

[6] Zhang, D., Automated Biometrics: Technologies and Systems, 2000, Norwell, MA: Kluwer Academic Publishers. 331.
[7] Allan, A., Biometric Authentication. Perspective. Gartner Research, 2002a: p. 1-31.

[8] HARRIS, A.J. and D.C. YEN, Biometric authentication: assuring access to information. Information Management andComputer Security, 2002.10 (1): p. 12-19.

[9] Dugelay, J.L., et al., Recent Advantages in Biometric Person Authentication, in ICASSP International Conference on Acoustics, Speech and Signal Processing. 2002: Orlando, Florida, USA.

[10] Woodward, J.D., et al., Army Biometric Applications: Identifying and Addressing Sociocultural Concerns. 2001:RAND.

[11] Chris Velazco.2011."Android Still Most Popular Smartphone OS, iOS Holds Steady In Second Place", (on-line), Techcrunch web. http://techcrunch. com/2011/11/03/android-still-most-popular-os-iosholds-steady-in-second-place/. 13 Januari 2013.

[12] Tyler Lee.2011."AuthenTec releases SDK for fingerprint sensor applications on Android phones", (on-line), Ubergizmo web. http://www.ubergizmo. com/2011/08/authentec-releases-sdk-for-fingerprintsensor-applications-on-android-phones/. 13 Januari 2013.

[13] Darcey Lauren., \& Conder Shane.2011. "Enable a Fingerprint Scanner for Android on the Motorola ATRIX 4G", (on-line), developer.com web. http:// www.developer.com/ws/android/devices/enable-afingerprint-scanner-for-android-on-the-motorolaatrix-4g.html. 13 Januari 2013

[14] Sandi Fajar Rodiyansyah.2011. "Arsitektur Sistem Operasi Android”, (online), educnologyweb. http://educnology.web.id/opensource/rodiyansyah/ arsitektur-sistem-operasi-android, 14 Januari 2013

[15] Dransfield, Robert. Human Resource Management. 2000: Heinemann Educational Publisher.

[16] Bredin, K., Human Resource Management in ProjectBased Organisations. 2008 - Challenges, Changes, and Capabilities. Doctoral thesis, Department of Management and Engineering, Linköping University, Linköping.

[17] M.S Cardon., \& C.E. Stevens., Managing Human Resources in Small Organizations: What do we know?, Human Resource Management Review, vol 14 (2004), pp. 295-323.

[18] Eugene McKenna., \& Nic Beech., Human Resource Management: A Concise Analysis. 2008, FT Prentice Hall. 